\title{
Correction to: Formulae recently proposed to estimate renal glomerular filtration rate improve the prediction of carboplatin clearance
}

\author{
Melanie White-Koning ${ }^{1,2} \cdot$ Marie Noëlle Paludetto ${ }^{1,2,3} \cdot$ Félicien Le Louedec $^{1,3} \cdot$ Laurence Gladieff $^{4}$. \\ Christine Chevreau ${ }^{4} \cdot$ Etienne Chatelut $^{1,2} \cdot$ Florent Puisset $^{1,2,3}$
}

Published online: 13 April 2021

(c) Springer-Verlag GmbH Germany, part of Springer Nature 2021

\section{Correction to: \\ Cancer Chemotherapy and Pharmacology (2020) 85:585-592 \\ https://doi.org/10.1007/s00280-019-04020-z}

The authors wish to report two errors in the formulae in Table 1 concerning the formulae used to estimate creatinine clearance.

In the BSA adjusted CKD-EPI formula (Calvert-CKDEPI) [1], the formula for eGFR should read.

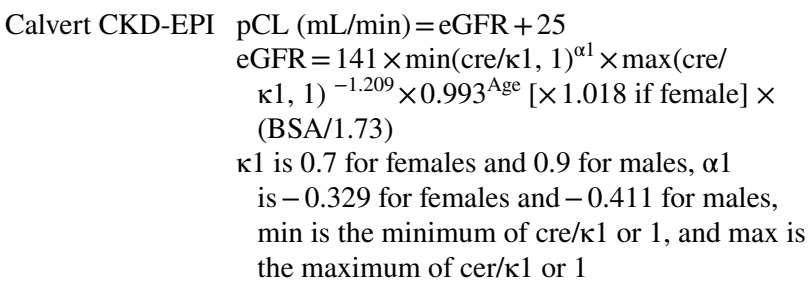

cre serum creatinin $(\mathrm{mg} / \mathrm{dL}), B S A$ body surface area $\left(\mathrm{m}^{2}\right)$

The original article can be found online at https://doi.org/10.1007/ s00280-019-04020-z

Florent Puisset

puisset.florent@iuct-oncopole.fr

1 Centre de Recherches en Cancérologie de Toulouse (CRCT), INSERM UMR1037, 2 Avenue Hubert Curien, CS53717, 31037 Toulouse CEDEX 1, France

2 Université Paul Sabatier Toulouse III, Université de Toulouse, 118 Route de Narbonne, 31062 Toulouse CEDEX 9, France

3 Pharmacy Department, Institut Universitaire du Cancer Toulousain (IUCT) Oncopole, Institut Claudius Regaud, 1 avenue Irène Joliot-Curie, Toulouse CEDEX 9 31059, France

4 Oncology Department, Institut Universitaire du Cancer Toulousain (IUCT) Oncopole, Institut Claudius Regaud, 1 avenue Irène Joliot-Curie, Toulouse CEDEX 9 31059, France
Similarly, in the BSA adjusted CKD-EPI creatinine-cystatin equation (Calvert-CKD-EPI_cys) [2] the formula for eGFR should read.

\begin{tabular}{|c|c|}
\hline Calvert CKD-EPI-cysC & $\begin{array}{l}\mathrm{pCL}(\mathrm{mL} / \mathrm{min})=\mathrm{eGFR}+25 \\
\mathrm{eGFR}=135 \times \min (\mathrm{cre} / \kappa 2, \\
1)^{\alpha 2} \times \max (\mathrm{cre} / \mathrm{\kappa} 2,1)^{-0.601} \\
\times \min (\mathrm{Cys} \mathrm{C} / 0.8, \\
1)^{-0.375} \times \max (\mathrm{CysC} / 0.8,1)^{-0.711} \\
\times 0.995^{\mathrm{Age}}[\times 0.969 \text { if female }] \times \\
(\mathrm{BSA} / 1.73) \\
\kappa 2 \text { is } 0.7 \text { for females and } 0.9 \text { for } \\
\text { males, } \alpha 2 \text { is }-0.248 \text { for females } \\
\text { and }-0.207 \text { for males, min indi- } \\
\text { cates the minimum of cre } / \kappa 2 \text { or } 1, \\
\text { and max indicates the maximum } \\
\text { of cre/ } 2 \text { or } 1\end{array}$ \\
\hline
\end{tabular}

cre serum creatinin $(\mathrm{mg} / \mathrm{dL}), C y s C$ serum cystatin $\mathrm{C}(\mathrm{mg} / \mathrm{L}), B S A$ body surface area $\left(\mathrm{m}^{2}\right)$

\section{References}

1. Levey AS, Stevens LA, Schmid CH, Zhang YL, Castro AF, Feldman $\mathrm{HI}$ et al (2009) A new equation to estimate glomerular filtration rate. Ann Intern Med 150:604-612

2. Inker LA, Schmid CH, Tighiouart H, Eckfeldt JH, Feldman HI, Greene $\mathrm{T}$ et al (2012) Estimating glomerular filtration rate from serum creatinine and cystatin C. N Engl J Med 367:20-29. https:// doi.org/10.1056/NEJMoa1114248

Publisher's Note Springer Nature remains neutral with regard to jurisdictional claims in published maps and institutional affiliations. 